\title{
INQUIETAÇÕES INTERCULTURAIS: UMA ANÁLISE NA MOTIVAÇÃO MIGRATÓRIA HAITIANA
}

\author{
Thayza Karolline de Souza Benetti ${ }^{1}$ \\ Rafael Pinto Duarte ${ }^{2}$
}

RESUMO: Compreendendo um estudo histórico contínuo, em que se faz uma análise a partir do entendimento de continuidade temporal, neste caso, a respeito da razão do movimento de migração da população haitiana, este artigo buscará como objetivo geral, conhecer a história haitiana a partir de marco temporal específico, como a sua independência, trilhando a Revolução Haitiana, até os dias atuais, assim como sua integração no Brasil entendendo o ponto de vista social, racial e regional. Para além, pensa-se na manutenção da identidade cultural. Dessa forma, para responder os objetivos específicos, com base na visão intercultural, os resultados foram apresentar da perspectiva do direito internacional, abrangendo direitos humanos, analisando essas condições atreladas às razões de deslocamento em um contexto de um mundo cada vez mais globalizado e os impactos dessa condição, abrangendo não apenas problemáticas, mas os benefícios da integração.

Palavras-chave: Direitos Humanos. Refugiados. Direito Internacional. Descolonização. Integração. Haiti.

\footnotetext{
I Bacharelanda em Relações Internacionais do $7^{\underline{0}}$ semestre do IESB Centro Universitário, em Brasília e pesquisadora em Relações Internacionais. Foi bolsista de Iniciação Científica pelo PIBIC/Bolsa IESB (2020/202I), com o tema "Mediação Intercultural e a Atuação em Conjunto com Organismos Internacionais". E-mail: thayzabenetti@gmail.com.

${ }^{2}$ Professor de Relações Internacionais e Direito do IESB Centro Universitário, em Brasília. Mestre em Desenvolvimento Sustentável, na área de concentração Política e Gestão da C\&T pelo Centro de Desenvolvimento Sustentável da Universidade de Brasília (UnB-CDS) e Bacharel em Relações Internacionais pela Universidade Católica de Brasília - UCB.
} 
ABSTRACT: Comprising a continuous historical study, in which an analysis is made from the understanding of temporal continuity, in this case, about the reason for the migration movement of the Haitian population, this article will seek - as a general objective, to know the Haitian history from specific time frame, such as its independence, following the Haitian Revolution, up to the present day, as well as its integration in Brazil, understanding the social, racial and regional point of view. In addition, the maintenance of cultural identity is considered. Thereby, to respond to the specific objectives, based on the intercultural vision, the results were presented from the perspective of International Law, covering human rights, analyzing these conditions linked to the reasons for displacement in a context of an increasingly globalized world and the impacts of this condition, encompassing not only problems, but the benefits of integration.

Keywords: Human Rights. Refugees. International rights. Decolonization. Integration. Haiti.

\section{INTRODUÇÃO}

O presente trabalho busca compreender o enfrentamento dos desafios do universalismo etnocêntrico com base em objetivo geral que tange a compreensão da história haitiana, levantando inquietações culturais como razão de deslocamento, através da análise que abarca vários recortes, principalmente no que se refere a raça em tempos coloniais.

Com o multilateralismo emanado após o II de setembro, é chegada a inserção de novos atores, bem como a sociedade civil com um forte caráter de solidariedade. Entretanto, esta não possui poder jurídico, tampouco legitimidade para agir sem a união de organismos multilaterais e apoio governamental doméstico. 
Desta forma, busca-se entender para atender os objetivos específicos, a importância de nomenclaturas juridicamente reconhecidas, neste caso os aspectos de migração e refúgio, considerando questões de permanência e acolhimento, com ênfase na construção da identidade nacional, inclusive o impacto dessa questão na cultura.

Para além, entende-se os aspectos socioculturais e econômicos através da óptica de análise de diferentes realidades. Logo, o trabalho enxerga também a importância do papel do mediador, considerando neste caso, o aspecto histórico haitiano, para que esse indivíduo possa ter uma vida digna e segura, sem o sentimento de não pertencimento, de ser o "Outro", sem que haja um apagamento cultural.

Para isso, é importante se afastar das amarras etnocêntricas, com suporte governamental através de políticas públicas em conjunto com a sociedade civil e organismos internacionais para que resguarde os Direitos Humanos, principalmente no que tange os processos de diáspora.

Dessa forma, o aspecto descritivo da pesquisa em união com análises de entrevistas dos migrantes em regiões brasileiras, permitiu observar, analisar e correlacionar as variáveis sem manipulá-las sob um contexto exploratório que segundo Cervo e Bervian (2007, p. 63), “a pesquisa exploratória realiza descrições precisas da situação e quer descobrir as relações existentes entre seus elementos componentes”. Com um planejamento bastante flexível para possibilitar a consideração dos mais diversos aspectos de um problema ou de uma situação, assim,

\footnotetext{
3 Conceito extraído da crítica e teórica indiana, Gayatri Spivak, em que o "Outro", é todo aquele que está na margem por sua condição de colonizado; subordinado pelos atos de colonização através da imposição da cultura.
} 
a pesquisa bibliográfica explica o problema, utilizando as referências bibliográficas publicadas e selecionadas. (RAMPAZZO, 2002).

\section{HAITI E SUA REVOLUÇÃO: HISTÓRIA E MOTIVAÇÃO MIGRATÓRIA}

A história do Haiti se diferencia da maioria das regiões da América Latina no contexto colonizador, sendo ocupado por Colombo em I492 na procura de cultivo e ouro em uma terra rica em metal amarelo (SANTOS, 2018), passando para o domínio francês no final do século XVIII, sendo o território francês que mais prosperou quando ainda se chamava São Domingos, e como consequência das explorações europeias, das ideias e episódios que levaram à Revolução Francesa ganhando maior autonomia e representatividade, desencadeando disputas internas entre brancos e negros no período de i971.

Logo, levando em consideração todo o feito e o resultado de ter a região

legitimada como o primeiro país negro fora de África - única revolução escrava e negra vitoriosa do mundo moderno, compreende-se, naquele período em que foi o segundo país das Américas a se tornar independente com Jaccques Dessalines, no ano de I804, o impacto que foi gerado no sistema que dirigia as regiões.

Acabou por despertar rebeliões buscando liberdade em outras regiões latinas, ou seja, como analisado por Washignton Nascimento (2008) "influiu em um grande medo de que uma insurreição daquela escala acontecesse em outros lugares da América escravista", sendo exemplo de revolução anticolonialista exitosa e contribuiu para a emancipação das colônias espanholas.

A revolução começou a ter um impacto na França, com a criação da Declaração dos Direitos do Homem e do Cidadão, em 26 de agosto de 1789, votada 
pela Assembléia Constituinte - como consequência do impacto da Declaração, colonos e deputados se sentiram ameaçados com a possibilidade de uma revolta, dessa forma tentando anular o documento.

Emergiu o Débito da Independência para o $\mathrm{Haiti}^{4}$, com consequências severas, que não apenas no sentido socioeconômico, mas uma forma de perdurar a posição de subserviência, em que a população não entendia a razão pela qual estavam pagando para seus antigos colonizadores algo que não devia, algo que foi guerreado e vencido, que porém, persiste até hoje, emergindo na população o pensamentos de que o "país foi forçado a comprar reconhecimento de uma independência que seu povo havia ganhado no campo de batalha" (SANTOS, 2018, p.I5), mesmo havendo a garantia do controle soberano econômico em seus artigos I2으 e $13^{\circ}$ da Constituição.

Válido ressaltar que a estrutura de poder era mantida pelo poder do racismo das elites dirigentes das Américas, incluindo a brasileira, em que que definiram a longo prazo as políticas internacionais que condicionam a antiga região de São Domingos, à marginalização e pobreza, política essa, que foi iniciada por Simón Bolívar, mesmo que tenha tido um apoio dos haitianos, acabou por excluir o Haiti dos países participantes para a Conferência do Panamá, em I826.

Sendo um reflexo que persiste nos tempos atuais nas relações de poder do sistema internacional, mesmo que anárquico, sabe-se que há uma disputa de poder entre os Estados que gera uma hierarquia nas relações. Quando não há uma ideal

\footnotetext{
4 Logo depois da declaração de independência em 1804 do Haiti, a França recusou-se a reconhecer sua independência como um país de ex-colonos e o governo napoleônico continuou a discutir planos para reocupar o território, mas as guerras napoleônicas mantiveram o Haiti protegido, especialmente a marinha britânica que barrou o exército francês. Larissa dos Santos (2018)
} 
inserção na dinâmica internacional do trabalho, não se abre espaço para uma competição, o que explica a manutenção das mazelas.

Essa ação vista como "força moral branca", se sobrepunha aos interesses negros que eventualmente acabou culminando no desejo de se expandir para outros lugares para ter oportunidades, de forma em que o Haiti se tornou uma das regiões com maiores relatos e, de certa forma, uma cultura no fluxo de migração, como analisado em entrevistas com imigrantes em regiões brasileiras, como a região metropolitana de Curitiba e São Paulo, essa última que serviu de inspiração para a canção "Um corpo no mundo", de Luedji Luna, em que remete a travessia e descolocamento como visto na sinopse do álbum da cantora. A mesma reflete:

\footnotetext{
"Quando a gente sai de um lugar para o outro, a gente começa a entender como impacta a solidão de não se ver representado. E São Paulo me trouxe isso. Eu andava pela cidade e não me via. Isso me incomodava. Ali, eu tinha uma outra dimensão da solidão. Eu estava só, sem meu pai, minha mãe e meus amigos. Era a solidão de um corpo invisível."
}

\section{MOTIVAÇÃO DA MIGRAÇÃO}

Essas medidas autoritárias se constroem de forma arbitrária, sendo obstáculos de acesso ao "Norte Global”, somando-se ao grave surto de cólera que ocorreu dez meses após o desastre ambiental, milhares de haitianos optaram por fugir da situação precária em seu país de origem rumando para países da América do Sul (THOMAZ, 2013, p. 132).

Logo, isso se torna um ponto chave para a ida dos haitianos em direção à Cuba em 1915, em um número vinte vezes superior ao do ano anterior (PINTO, 20Io, p. 83I), sendo a oportunidade dos EUA de utilizar o Haiti como fornecedor de mão de obra barata, assim como os países vizinhos o fizeram. 
A partir disso, passa-se a compreender a motivação do artigo no que tange a fortificação da cultura e a volta aos modelos dos ancestrais revolucionários, de ocupação e habitação digna desses corpos em qualquer região do mundo, pelos Direitos Humanos Universais, sem que sofram xenofobia e racismo, evitando essa sensação de não pertencimento, constantemente vista historicamente.

Sensação essa que vem perseverando desde essa ação colonizadora no Haiti, em que mesmo os nativos passaram a não pertencer a região e, os povos africanos arrancados de sua terra procurando pertencimento, acabaram se encontrando em posição e exploração subserviência, com apagamento de suas origens no âmbito social e cultural.

\section{O LEGADO DE DUAS CRISES: 1988 E 2004}

Como reflexo de um período que reverbera as consequências da manutenção do neocolonialismo instaurado, a instabilidade vivida através do controle estadunidense por aproximadamente 25 anos, até a troca de poder em 1957, com François Duvalier, foi marcado por uma série de agressões e violências entre os dirigentes opositores e a população civil, sob tutela do governo dos Estados Unidos, como analisado por Gelfenstein (2021), até 1986.

Apesar do permanente quadro de instabilidade política e seus reflexos nos âmbitos social e econômico do Haiti, foi apenas com a deposição de Jean-Bertrand Aristide - eleito presidente do país, em 1990, pelo partido comunista e com amplo apoio das camadas pobres da sociedade - que a comunidade internacional se voltou para a problemática haitiana. 
O objetivo da Missão das Nações Unidas no Haiti (UNMIH) era recolocar Aristide, legitimamente eleito no poder, em um período que não contava com a cooperação das autoridades militares - logo não sucedeu em outros aspectos, mas Aristide foi reconduzido à presidência Após as eleições de 1996, com vitória de René Préval, a ONU enviou outra operação de paz à Missão de Suporte das Nações Unidas no Haiti (UNSMIH), que perdurou até 1997.

Em suma, é possível relatar a falha das missões, primeiramente com a necessidade de criação de várias em sequência - por mais que algumas, com o objetivo de filtrar e serem mais específicas. Elas apresentam falhas na efetividade das operações de manutenção de paz na década em apreço, devido a camadas de crise envolvendo política, social e econômica ao passar dos séculos - devido a fatores externos e internos.

Exemplo disso, é a necessidade de estabelecer a MINUSTAH em solo haitiano, pontuados por Castor (1995, apud CORBELLINI, 2009, p. 97) através de cinco fatores, em que dentro deste artigo não cabe especificar cada um deles, apenas apresentar e contextualizar o cenário para compreensão crítica e cronológica.

O primeiro remete aos anos de ditadura duvalierista (CASTOR, 1996, p. 2, apud CORBELLINI, 2009, p. 98), ocorrido entre os anos de 1957 e 1986, causando desmonte das instituições estatais e desmobilização da população, além de não ter influenciado o desenvolvimento, levando ao segundo ponto após a institucionalização dos tonton macoutes ${ }^{5}$, que culminou no país saqueado e retalhado, com forte polarização e cicatrizes psicológicas e materiais.

\footnotetext{
5 Um grupo de milícia rural, com objetivo de obter o controle do interior rural coordenado por Duvalier. Culturalmente, os tonton macoutes, na tradução livre seria "bicho papão", representando uma figura de autoridade hierárquica de punição metafisicamente. Research in African Literatures
} 
Devido a essa situação, a autora Corbellini (2009, p. 98) leva ao terceiro ponto de viés interno, no momento em que urge a busca por mudança, emergindo assim, novos atores sociais e uma sociedade civil organizada, a partir da segunda metade da década de 1970, na luta pela democracia e renovação do sistema político.

Os dois últimos fatores, são externos: presença de força estrangeira constante na década de 90 e um novo contexto das relações internacionais, marcado pelo fim da Guerra Fria, e suas consequências para o Terceiro mundo (CASTOR, 1995, p. 3, apud CORBELLINI, 2009, p. 98), que levam a compreensão do panorama político de 2004, com a queda do então presidente Aristide, e por consequência a fortificação e manutenção da intervenção internacional

Apesar de um período de chamada por ajuda, inclusive do Conselho de Segurança da ONU, houve da mesma forma, aprofundamento da crise política, com uma série de eventos que incluíram conflito armado, com o país sendo segregado por esses bandos e surgimento de insurgentes oposicionistas no Norte, ligados ao regime duvalierista.

Como resultado à busca do CSNU, surgiu a Resolução I529 (2004), determinando o estabelecimento de uma Força Multinacional de Paz, provisória, a ser enviada no território haitiniano (CORBELLINI, 2009, p.I0o), composta por EUA, França, Chile e Canadá, com o objetivo de garantir a governabilidade para o então presidente da Suprema Corte do país, Boniface Alexandre, e preparar o país para as tropas da nova operação no país, a conhecida MINUSTAH, que foi autorizada posteriormente - ainda no mesmo ano, através da Resolução 1542.

Vol. 35, No. 2, Haiti, I804-2004: Literature, Culture, and Art (Summer, 2004) 
Um Estado que era expressão de uma oligarquia esclerosada (de militares, de homens de negócios ou de políticos) não consegue - apesar das influências de modernismo importadas do estrangeiro pela forma de capital ou de modelo - gerir uma sociedade nem estimular as forças motrizes suscetíveis de garantir seu desenvolvimento.

\section{ESTUDO EPISTEMOLÓGICO DA MIGRAÇÃO E A INTEGRAÇÃO DENTRO DAS LEIS DOS ESTADOS}

A situação da região caribenha dentro de processos coloniais e de um racismo tecnológico e científico advindos da globalização, levam a um processo de extração e empobrecimento dessa região, fazendo com que a situação regional ganhasse uma marca como pertencente do "terceiro mundo", que por consequência leva a uma movimentação para além das fronteiras, com o grande fluxo de refugiados e migrantes, assim como regiões de asilo.

Além das condições que o colonialismo deixou e as contradições ressaltadas ainda nesse artigo, o período de ocupação dos EUA entre 1915 e 1934 é marcado por agravamento das condições do meio rural, com expropriações de terra e penetração desta nação no Haiti, de forma abrupta, a ponto de alterar a lei que desde a fundação da república não permitia a posse de terra aos estrangeiros (PINTO, 2010, p.831). Logo, isso se torna um ponto chave para a ida dos haitianos em direção à Cuba em 1915, em um número vinte vezes superior ao do ano anterior (PINTO, 2010, p.831), sendo a oportunidade dos EUA de utilizar o Haiti como fornecedor de mão de obra barata, assim como os países vizinhos o fizeram.

Vale ressaltar que a compreensão das nomenclaturas é de extrema importância para o reconhecimento do Direito Internacional. 
Dentre outros fatores, há a problemática em torno do reconhecimento da diáspora haitiana após o terremoto, pois o termo "refugiado" da Convenção das Nações Unidas relativa ao Estatuto dos Refugiados (I95I), não inclui essa movimentação.

Por isso, muitas leituras reconhecem o termo de "migração forçada" e defendem a existência de um "regime internacional relativo aos refugiados" (Benz; Hasenclever, 2011, p. 187 apud Thomaz, 2013, p. 134), pois esta abarca a questão de desastres naturais e não apenas perseguição por motivos de raça, religião, nacionalidade, pertença a grupo social ou opinião política.

Entretanto, o termo foi expandido, como analisado por Thomaz (2013), frente a um crescente número de pessoas que também precisavam de assistência e proteção internacional, uma vez situadas fora de seu país de origem, - mas que não se enquadram nesse escopo normativo, mudando juntamente com os contextos políticos globais e regionais ao longo do tempo, constando

[...] pelos Estados - a resposta deve ser de maneira conjunta internacionalmente para proteger e assegurar os direitos daqueles que não podiam contar com seu país de origem para tanto, oferecendo assim uma "proteção substituta" para esses migrantes. Diana Thomaz (2013)

Entretanto, pensando nessas terminologias e como também a decisão de como incluir quem é visto como o "outro" em seu Estado contém um grande caráter político, principalmente na política moderna

[o] Comitê Nacional para Refugiados (CONARE) - o órgão público responsável por deliberar acerca da concessão do status de refugiado - chegou à conclusão de que os deslocados haitianos não poderiam ser considerados refugiados, a despeito da legislação nacional ampla sobre a questão. As razões para a negativa assinalavam que os haitianos não podiam demonstrar claramente a existência de uma ameaça a suas vidas, segurança 
ou liberdade. Além disso, o CONARE também apontou que a proteção daqueles que eram incapazes ou não tinham vontade de voltar a seu país de origem devido a catástrofes naturais ou pobreza não era compreendida no escopo da Convenção de 1951 ou na lei brasileira. Godoy, 2011 apud Thomaz, 2013, p. 138

Afinal, apesar de tratados e entendimentos e determinações legais, no final recai sobre o Estado a capacidade de agência e autodefinição dos migrantes, o que se relaciona diretamente com o status da soberania, pois com a "concessão ou não da proteção aos solicitantes de refúgio, não apenas uma determinação humanitária está sendo feita, mas essa também é uma situação em que o Estado “(re)funda sua reivindicação de monopólio do político" (Nyers, 2003, p. I07ı apud Thomaz, 2013, p 137).

Tendo isso em vista, compreende-se a importante posição que o Brasil ocupa no avanço desses direitos e reconhecimento, tendo sido o primeiro país do subcontinente a aprovar uma lei específica sobre refúgio em 1997 (período pósredemocratização), a Lei 9.474 de 22 de julho abarcando "grave e generalizada violação de direitos humanos" (Lei № 9.474, 1997), como visto por Thomaz (2013), como uma das razões legítimas para a concessão do refúgio, além dos fatores de perseguição já abarcados na Convenção de 1951.

Por isso, muitas leituras reconhecem o termo de "migração forçada" e defendem a existência de um "regime internacional relativo aos refugiados" (Benz; Hasenclever, 2011, p. 187 apud Thomaz, 2013, p. 134), pois esta abarca a questão de desastres naturais e não apenas perseguição por motivos de raça, religião, nacionalidade, pertença a grupo social ou opinião política.

Dentro de fóruns internacionais e nacionais o termo mais presente é “migrações internacionais”, logo, é legitimado e garante uma visibilidade do tema, 
mas carrega também complexidades por não diferir as interligações no âmbito social, econômico, jurídico, cultural e institucional na movimentação de fronteiras - com a alteração da residência habitual, com travessia da fronteira política impostas pelas estruturas do capitalismo, que ressaltam essa divisão econômica entre as regiões, reforçando uma hierarquia e dependência (Keely, 200o, apud Rodrigues, 2010, p. 854).

Dessa forma, apesar de o ACNUR considerar refugiados (migração de refúgio, de acordo com a Convenção Relativa ao Status dos Refugiados de 1951 (Convenção de 5I) aqueles que "por motivos de raça, religião, nacionalidade, grupo social ou opiniões políticas encontre-se fora de seu país de nacionalidade e não possa ou não queira acolher-se à proteção de tal país" e, que por isso não possa estar e/ou não queira regressar a sua residência habitual; e também por motivo grave de violação de direitos humanos, sendo obrigado a buscar refúgio em outros país, ainda há debates quanto ao reconhecimento das migrações ambientais.

Considerando as gerações dos direitos humanos, cujas abraçam a questão do direito à propriedade - bem como direito à moradia adequada, compreende-se que em caso de mudanças no ambiente que passam por afetar negativamente as vidas e suas condições, quando se é obrigado a se deslocar de suas casas habituais, seja permanente ou temporariamente, sendo em seu território ou no estrangeiro, deveria ser protegido pela Convenção Relativa ao Status dos Refugiados, que em sua norma presente desde I95I, não reconhece os deslocamento por essa causa.

Essa situação, passa por desencadear conflitos transnacionais que afetam as fronteiras e deixam esses migrantes em situação de completa vulnerabilidade, tendo em vista, que como afirmado para Keohane, "as mudanças climáticas têm alterado o fluxo e refluxo de populações humanas por milhares de anos". Apenas na década 
de 7o, surgiu a expressão "refugiado ambiental", cunhada por Lester Brown do Worldwatch Institute mas só foi popularizada com a publicação, em 1985, por Essam El- Hinnawi, professor do Egyptian National Research Centre, Cairo (Rodrigues, 2010, p. 857).

Para contextualizar o avanço da aceitação do conceito de "migração ambiental”, os haitianos pós-terremoto foram acolhidos, como visto por Rodrigues (2010), em território brasileiro pelo Estatuto do Estrangeiro (Lei 6.815/80)I715, já obsoleto, e substituído pela nova Lei de Migrações (Lei 13.445 de 2017, em vigor em novembro de 2017).

Ademais disso, a relação entre o ponto de vista negativo do CONARE e o Brasil, permeiam em algo que resultou no visto humanitário concedido pelo Brasil através do CNIg, devido a demanda dos migrantes haitianos de uma permissão especial para permanecer no Brasil, devido a situação - que apesar de não ser reconhecida amplamente, mas é um fato que impede que vivam gozando do que as gerações dos Direitos Humanos acobertam devido ao desastre natural. Sendo assim, o Brasil se posicionou de maneira distinta aos EUA e França que negaram a entrada em seus territórios, mas de primeira mão os negou o status de refugiados.

Outra participação importante do país, além de encaminhar projetos de reassentamento desde 200 I e apoiar reuniões regionais e planos de ação comuns para a proteção dos refugiados, foi legalizar isto através da Declaração de Brasília sobre a Proteção de Refugiados e Apátridas no Continente Americano de 2010.

\section{CONCLUSÃO}

Dessa forma, atingiu objetivos específicos entendendo como os processos coloniais afetaram e, ainda afetam as antigas colônias, bem como o impacto da 
globalização sob os grandes índices migratórios, por uma somatória de fatores analisados.

A pergunta original tem como cerne responder, como o passado colonial repercute na política global contemporânea. Sendo visto assim, que há uma responsabilidade pelos rastros de vulnerabilidade deixados neste período, bem como a tentativa de reparar, sendo a identidade nacional um assunto a ser explorado em outros estudos.

Foi possível enxergar uma ligação direta entre a situação atual do Haiti e sua cultura de migração, com os fatores coloniais, como isso, atinge em escala global a posição e margem de manobra do país para desenvolvimento, bem como o grande aumento dessa movimentação ocorreu no processo das crises políticas e sociais.

Entretanto, não apenas isso, como a questão do terremoto na época terminou por arrasar completamente o país, forçando um movimento migratório ainda mais acentuado, havendo um denso número de pedidos de refúgio entre 2000 e 2010 .

Sendo que o número de solicitações de refúgio foi de aproximadamente 453 no ano de 2010, de acordo Ministério da Justiça, Departamento de Polícia Federal, Sistema de Solicitação de Refúgio, aumentou aproximadamente 37 vezes no ano de 2014, no Estado brasileiro. Logo, o Brasil passa a se tornar uma região de asilo para essa população, principalmente com as concessões do visto humanitário.

Neste contexto, destaca-se a importância do Direito Internacional, em termos de reconhecimento de nomenclaturas e a importância do cuidado epistemológico para os Direitos Humanos. Aplicando no Brasil uma reflexão quanto às questões sobre política migratória, legislação, cultura, raça, gênero, identidade, por exemplo. 
Além disso, como a globalização é um fator que cobra responsabilidade histórica, visto as amarras de interdependência, junto a necessidade de cooperação, mas com atenção aos interesses e posição de manutenção de subserviência. Também, compreender como esses imigrantes são inseridos e quais políticas públicas, no âmbito doméstico e internacional, a partir das lentes da motivação histórica.

A situação da região caribenha dentro de processos coloniais e de um racismo tecnológico e científico advindos da globalização e institucionalização do mesmo, levam a um processo de extração e empobrecimento dessa região, fazendo com que a situação regional ganhasse uma marca como pertencente do "terceiro mundo", que por consequência leva a uma movimentação para além das fronteiras, com o grande fluxo de refugiados e migrantes, assim como regiões de asilo.

\section{REFERÊNCIAS BIBLIOGRÁFICAS}

ACNUR (2016). Declaração de Nova York é "uma oportunidade única" para refugiados, afirma Chefe de Proteção do ACNUR. Disponível em: <https://www.acnur.org/portugues/2016/o9/30/declaracao-de-nova-york-e-umaoportunidade-unica-para-refugiados-afirma-chefe-de-protecao-do-acnur/>. Acesso em: 8 jul. 202I

BAENINGER, Rosana; PERES, Roberta. Migração de crise: a migração haitiana para o Brasil. Revista Brasileira de estudos de População, v. 34, p. II9-I43, 2017.

BRITO, Maíra de Deus. A música diaspórica de Luedji Luna. Revista Seca. 3I de outubro de 2017. Disponível em: <https://revistaseca.com/artigos/a-musicadiasporica-de-luedji-luna/>. Acesso em: 8 abr. 202I.

COGO, Denise. Haitianos no Brasil. Comunicação e interação em redes migratórias transnacionais. Chasqui. Revista Latinoamericana de Comunicacion, n. 125, p. 23-32, 2014. 
CORBELLINI, Mariana Dalalana. Haiti: da crise à MINUSTAH. 2009.

Diretrizes Curriculares Nacionais para a Educação das Relações Étnico-Raciais

e para o Ensino de História e Cultura Afro-Brasileira e Africana - CONSELHO NACIONAL DE EDUCAÇÃO/CONSELHO PLENO/DF. Ministério da Educação. Disponível em: <http://portal.inep.gov.br/documents/I86968/484184/Diretrizes+curriculares+na cional+para+a+educa ${ }_{0} \mathrm{C}_{3} \% \mathrm{~A}_{7} \% \mathrm{C}_{3} \% \mathrm{~A}_{30}+\mathrm{das}+$ rela $\% \mathrm{C}_{3} \% \mathrm{~A}_{7} \% \mathrm{C}_{3} \% \mathrm{~B}_{5} \mathrm{es}+\% \mathrm{C}_{3} \% \mathrm{~A}_{9}$ tnico-raciais+e+para+o+ensino+de+hist $\% \mathrm{C}_{3} \% \mathrm{~B}_{3}$ ria+e+cultura+afrobrasileira+e+africana/f66ce 7 ca-eoc8-4dbd-8df3-4c2783fo6386?version=1.2>. Acesso em: 04 de dezembro de 2019.

DOS SANTOS, Larissa. A REVOLUÇÃO HAITIANA E OS ECOS DE UMA INSURREIÇÃO NEGRA.

Entre Iguais e Diferentes: a Mediação Intercultural Atas das I Jornadas da Rede de Ensino Superior para a Mediação Intercultural. Alto Comissariado para as Migrações, I.P. (Coord.). Disponível em: <http://repositorio.esepf.pt/bitstream/20.500.11796/2374/I/Atas_RESMI_final.pdf >. Acesso em: 2i de setembro de 2019.

Fanon, F. (1968). Os Condenados da Terra. Rio de Janeiro, RJ: Editora Civilização Brasileira.

FERREIRA, Francisca Jéssica Santos. Multiculturalismo e Educação. Disponível em <https://meuartigo.brasilescola.uol.com.br/educacao/multiculturalismoeducacao.htm>. Acesso em: 2I de janeiro de 2020.

GELFENSTEIN, Sergio Rodriguez. Haiti: um país vítima do ódio e da exploração das potências há 200 anos. Brasil de Fato. São Paulo, 7 de fevereiro de 202I. Disponível em: <https://www.brasildefato.com.br/2021/o2/o7/artigo-haiti-umpais-vitima-do-odio-e-da-exploracao-das-potencias-ha-20o-anos $>$. Acesso em: 9 mar. 2021.

IVENICKI, Ana; DE SOUZA, Renan Santiago. Multiculturalismo como política de inclusão/exclusão. Disponível em: 〈http://dx.doi.org/ı.14572/nuances.v27ir.3473〉. Acesso em: Io fev. 2020.

LAGUERRE, Michel S. Voodoo and politics in Haiti. Springer, 2016. 
LAKATOS, Eva Maria e MARCONI, Maria de Andrade. Fundamentos de metodologia científica. $4^{\underline{a}}$ ed. rev. e ampl. São Paulo: Editora Atlas, 2001.

LOGIS, Berno. A Revolução Haitiana (1791-1804) como momento privilegiado na construção de uma identidade "negra".

LÜDKE, Menga; ANDRÉ, E.D.A. Pesquisa em educação: abordagens qualitativas. São Paulo: EPU, 1986.

MAZZUOLI, Valerio de Oliveira. Curso de direito internacional público. 1o $^{\underline{a}}$ ed. São Paulo: Revista dos Tribunais, 2016.

MEDIAÇÃO SÓCIOCULTURAL - uma maneira coesa de inserir imigrantes e refugiados na sociedade. UNICuritiba, 2016. Disponível em: 〈https://even3.azureedge.net/anais/28305.pdf〉. Acesso em: 20 set. 2019.

NASCIMENTO, Washington Santos. "São Domingos, o grande São Domingos": repercussões e representações da Revolução Haitiana no Brasil escravista (I79I1840). Dimensões, n. 21, 2008.

OBMIGRA. Ministério do Trabalho. A imigração haitiana no Brasil:

Características demográficas na região Sul e no Distrito Federal. 2016.

O que são direitos humanos? Disponível em: 〈https://nacoesunidas.org/direitoshumanos/>. Acesso em: 29 set. de 2019.

RAMPAZZO, Lino. Metodologia Científica. São Paulo: Loyola, 2002.

SEGUY, Franck et al. A catástrofe de janeiro de 20ı, a" Internacional Comunitária" e a recolonização do Haiti. 2014.

THOMAZ, Diana Zacca. Migração haitiana para o Brasil pós-terremoto: indefinição normativa e implicações políticas. Primeiros Estudos, n. 4, p. I3I-I43, 2013.

VILLA, Rafael A. Duarte. Formas de influência das ONGs na política internacional contemporânea. Revista de Sociologia e Política, p. 21-33, 1999.

ZARRO, Susana Maria. Perspetivas de Integração por parte de Refugiados numa comunidade do Litoral de Portugal. Dissertação de mestrado, 2017. Disponível 
em:<https://iconline.ipleiria.pt/bitstream/ı040o.8/3020/I/DissertacaoMestradoS usanaZarro.pdf $>$. Acesso em: 20 set. 2019.

ZENI, Kaline; FILIPPIM, Eliane Salete. Migração haitiana para o Brasil: acolhimento e políticas públicas. Revista Pretexto, v. I5, n. 2, p. II-27, 2014. 